\title{
Best Practices for Social Media Governance and Strategy at the Humber College Institute of Technology and Advanced Learning
}

\author{
$1^{\text {st }}$ James Christopher Cullin \\ The Business School \\ Humber College Institute of Technology \\ and Advanced Learning \\ Toronto, Canada \\ james.cullin@humber.ca
}

\begin{abstract}
The purpose of this research project is to identify best practices for a cross-institutional social media framework for the Humber College Institute of Technology and Advanced Learning in Toronto, Canada. Many individual schools, divisions and departments within the college actively deploy social media, but do so in a manner that that is not formally coordinated with the institution's central marketing department, and furthermore, departmental use of tools such as Facebook, Twitter, Instagram and LinkedIn are not always tightly aligned with the institution's digital communications strategy. A descriptive survey consisting of 20 closed-ended questions and one open-ended question was designed to capture current practices in social media governance and strategy within the higher education sector. This web-based survey was completed by social media managers at 336 higher education institutions located in six different countries: Canada, the United States, Australia, New Zealand, Ireland, and the United Kingdom. The resulting data was synthesized with a literature review in order to establish recommendations for a social media governance framework for Humber that will allow the polytechnic to maximize the impact of social media platforms in the service of its student recruitment and broader promotional and community engagement efforts.
\end{abstract}

Keywords-social media best practices; social media governance; social media strategy; social media in higher education.

\section{INTRODUCTION}

The Humber College Institute of Technology and Advanced Learning is a publicly funded post-secondary institution located in Toronto, Canada. It was established by the Province of Ontario in 1967 as a College of Applied Arts and Technology. In 2013, the Board of Governors adopted a new strategic plan that solidified Humber's differentiation from traditional community colleges, by fully positioning the institution as a polytechnic. Humber's polytechnic identity is reflected in the range of credentials it offers, including bachelor's degrees, one- and two-year graduate certificates, two- and three-year diplomas, and a variety of apprenticeship programs [1]. This differentiated approach has allowed Humber to grow both domestic and international enrolments relative to other colleges in Ontario. The polytechnic enrolled about 27,500 students during the 2016-17 academic year, of which $16 \%$ were international [2].
Like most higher education institutions, Humber maintains a variety of social media channels to engage with staff, faculty, students, employers and the broader community. Since 2014, Humber has maintained a directory of college sanctioned social media accounts. In November 2014, that directory listed six college-wide social mediaaccounts, along with 14 additional accounts maintained by six of Humber's eight academic divisions. Additionally, the directory showed that four student support units maintained another 18 social media accounts [3]. Taken together, Humber had 38 officially sanctioned social media channels in late 2014. As of September 2018, that numbed had grown to over 120 accounts.

Although Humber was an early adopter of social media, establishing a Twitter presence in January 2009 followed by a Facebook presence the next month, the college has never adopted a formal, systematized framework for the coordinated use of social media across the institution [4] [5]. The lack of such a framework creates two problems for Humber. First, the lack of coordination runs contrary to the institution's Strategic Plan, which calls for Humber to move in the direction of greater coordination between operating units [1]. While Humber has become less siloed over time most visibly in the way academic operations and student support teams have come together to work more seamlessly - the college's use of social media remains siloed and uncoordinated. Second, the lack of a formalized strategic social media framework is preventing the college from maximizing the impact of digital media tools in the service of its recruitment, promotional, and community engagement efforts. Both domestically and globally, social media is the most meaningful vehicle available for communicating program availability and student success stories which are key to student recruitment. Together, the need to solve these two problems led to this research project being undertaken to answer the question, "What are the best practices for a crossinstitutional social media framework for the Humber College Institute of Technology and Advanced Learning?"

\section{A. Literature Review}

Social media platforms are a recent addition to the bundle of tools available to higher education communications specialists. LinkedIn is among the oldest social media websites still in use, having launched in May 2003 [6]. Facebook also has more history behind it relative to other social media platforms, having launched in February 2004 
[7]. Twitter emerged in March 2006 [8]. The two dominant photo sharing platforms, Instagram and Pinterest, were both launched early in this decade. Pinterest started in March 2010 and Instagram launched in late 2010 [9] [10]. The first video was uploaded to YouTube in April 2005, while Vine launched in January 2013 [11] [12]. Snapchat is also a very young platform, having first appeared in September 2011 [13]. Taken together, these eight social media platforms were available for use by communications specialists for an average of just 10 years by the start of 2017. Many of the more senior communications professionals working in higher education today would have completed their formal education prior to the emergence of social media as an important marketing and communications channel.

Smith observes that each of the major social media platforms affords higher education communications specialists a powerful mechanism to recruit new students, in addition to interacting with both current students and alumni, which are three of the most important market segments colleges seek to communicate with [14]. She further notes that circa 2015, Facebook, Twitter, and Instagram were best suited for engaging with prospective students, while LinkedIn and Facebook were best suited to reaching alumni. Smith stresses that while there is much speculation in the popular media around the decline of Facebook, the evidence does not back up such claims. Pew Research reported that Facebook remains the most popular platform with teens, the principal source of future students for higher education institutions, with $71 \%$ of people aged 13 to 17 using the service, according to a 2015 study [15]. The same Pew survey found that $52 \%$ of American teens use Instagram, while just 32\% use Twitter; and that Facebook was the dominant service among teens who use only one social media platform, with $66 \%$ of people aged 13 to 17 reporting they use Facebook. Pew reports that Instagram is far more popular with teenaged women (61\%) than with teenaged men (44\%), whereas Facebook usage skews slightly towards teenage boys $(72 \%)$ compared to teenage girls (70\%).

Constantinides \& Stagno observe that social media platforms have been shown to be cost-effective tools in extending a university's global recruitment reach [16]. Dennis et al. found that institutions that can foster a positive reputation among stakeholders hold a significant competitive advantage in recruiting new students within the crowded marketplace in which most colleges and universities operate[17]. Choudaha notes that in the first number of years of the social media revolution, academic leaders had access to relatively few tools to measure the impact of their use of available digital engagement platforms [18]. Bélanger et al. suggest that the lack of a social media presence would be detrimental to a university's reputation, but equal harm can accrue from maintaining a social media profile that users perceive as existing simply for the sake of the higher education institution having an account on that platform [19]. These researchers further contend that higher education leaders must ensure that social media is used in a way that engages the target audience so that institutional branding goals can be achieved. While social media platforms can be cost-effective and are characterized by low barriers of entry for practitioners, Choudaha also finds that measuring the human resources costs necessary to build institutional momentum has proved difficult for higher education leaders
[18] He points out that the nature of social media platforms is such that any member of the campus community can post messages that could have a widespread impact on the institution's reputation. Bélanger et al. argue that if social media practitioners across campus are not crafting messages that are properly aligned with institutional branding goals, they can inflict considerable damage to the university [19].

Tannou and Westerman found that both for-profit and not-for-profit organizations tend to use steering committees as their main governance vehicle for bridging silos and aligning social media activities at an organization-wide level [20]. The researchers also found that steering committees allow organizations to address three key issues: (a) How the organization prioritizes and funds digital initiatives in cases where the business case is unclear; (b) Crafting of internal rules that will establish a consistent customer experience online; and, (c) Identifying which social media functions should be managed centrally versus those that should be handled locally. Kane argues that social media success at an institution-wide level is less about employing specific platforms and tools, and more about cultivating an appropriate organizational climate [21]. Ansaldo found that developing a collection of social media policies, procedures and educational resources supports a governance framework that allows organizations to avoid policing their employees and instead empowers individuals to self-manage their efforts [22]. Mennie and Smith argue that developing a social media governance strategy is the best way to ensure that the negative fallout of any social media blunder will be minimized [23].

In their study of organizations that have achieved maturity in their approach to social media deployment, Li and Bernoff identified several common characteristics in how such organizations approach the adoption of a new social platform [24]. First, the messaging conveyed via the new channel has tight alignment and can be measured in relation to the organization's strategic objectives. Second, the channel is directed centrally but staffed by existing staff from a relevant department. Third, the channel's activities align with and amplify the organization's other social media efforts. Organizations with mature digital strategies were found to be almost twice as likely as non-mature entities to have assigned a single manager or functional group to lead their digital efforts, according to research conducted by Kane et al [25]. In this same research study, workers in digitally mature companies reported being very confident in the social media fluency of their leaders. In this context, fluency refers not to a mastery of technology, but rather to the capacity to articulate the importance of social platforms for the organization's future success.

Barrows observes that the pattern of adoption for social media within the higher education sector has been shaped in part by the decentralized nature of most colleges and universities [26]. This is to say that individual departments can easily adopt social media platforms without reference to the university's central communications team. He notes that New York University (NYU) housed over 1200 Twitter and Facebook accounts across campus in 2014 and it is simply not realistic to centrally manage such a large set of accounts. Instead, Barrows advocates a "hybrid social media strategy" for decentralized organizations like NYU, wherein the central communications team supports, collaborates with, 
and offers guidance to individual departments to support their social media efforts while also allowing them a high degree of independence in the way they use Facebook, Twitter and other social media platforms.

Piskorski proposes that organizations can leverage social media platforms using one or both of two distinct strategies: (a) Digital strategies and/or (b) Social strategies [27]. He describes digital strategies as porting the organization's existing marketing and/or customer acquisition processes to a given social platform and executing those processes in fundamentally the same manner as it has been doing on traditional media platforms. By contrast, in employing social strategies, the organization builds a social solution that results in either cost reductions, or an increased willingness by users to undertake tasks that benefit the organization for free. Piskorski argues that social strategies are more difficult to execute than digital strategies because they require the organization to first understand both the unmet economic and social needs of customers, and then to create solutions that meet both needs at the same time. A further challenge, he notes, is that social strategies oblige the organization to modify one or more elements of its value chain and relinquish control over that part of its operations to either customers or suppliers. Thus, Piskorski concludes, social strategies present a far greater risk to an organization than more traditional digital strategies, and increase the importance of maintaining robust digital and social media governance structures.

\section{RESEARCH METHODS}

The methodology for this research project took the form of a web-based survey that was completed by 336 social media managers across six countries: Canada, the United States, Australia, New Zealand, Ireland, and the United Kingdom. The survey was created in August 2014, based on insights gleaned from available literature, and refined through an ethics review board process in September of that year. Respondents completed the survey between October 2014 and January 2015. The survey consisted of 20 closedended questions and one open-ended question and was designed to capture current practices in social media governance and strategy within the higher education sector. The survey questions that are specifically referenced in this paper are listed in Table I.

\section{TABLE I. SURVEY QUESTIONS}

\begin{tabular}{|l|l|}
\hline Q4 & $\begin{array}{l}\text { Thinking about your institution's main } \\
\text { Facebook page, do you routinely share posts that } \\
\text { originated on other Facebook pages? }\end{array}$ \\
\hline Q6 & $\begin{array}{l}\text { Which of the following audiences do you } \\
\text { actively seek to reach via your institution's } \\
\text { primary Facebook page? }\end{array}$ \\
\hline Q10 & $\begin{array}{l}\text { Thinking about your institution's main Twitter } \\
\text { account, do you routinely “re-tweet" posts that } \\
\text { originated on other Twitter accounts? }\end{array}$ \\
\hline Q12 & $\begin{array}{l}\text { Which of the following audiences do you } \\
\text { actively seek to reach via your institution's } \\
\text { primary Twitter account? }\end{array}$ \\
\hline Q13 & $\begin{array}{l}\text { In addition to Facebook and Twitter, which of } \\
\text { the following social media platforms does your }\end{array}$ \\
\hline
\end{tabular}

\begin{tabular}{|l|l|}
\hline Q15 & $\begin{array}{l}\text { In addition to your institution-wide social media } \\
\text { platforms, does your college permit individual } \\
\text { departments / programs / schools to maintain } \\
\text { their own social media channels (Facebook, } \\
\text { Twitter, YouTube, etc)? }\end{array}$ \\
\hline Q16 & $\begin{array}{l}\text { Does your institution publish a "social media } \\
\text { policy" or some form of "social media } \\
\text { guidelines" or a "social media best practices" } \\
\text { document for individuals who manage college- } \\
\text { sanctioned social media channels such as a } \\
\text { departmental Facebook page or Twitter account? }\end{array}$ \\
\hline Q17 & $\begin{array}{l}\text { Which of the following social media platforms } \\
\text { are used by your institution's individual } \\
\text { departments / programs / schools? }\end{array}$ \\
\hline Q18 & $\begin{array}{l}\text { Does your college have some form of steering } \\
\text { committee or discussion group that facilitates } \\
\text { dialog between institution-wide social media } \\
\text { managers and departmental-level social media } \\
\text { managers? }\end{array}$ \\
\hline Surrey invitations were sent to 1,992 post-secondary
\end{tabular}

Survey invitations were sent to 1,992 post-secondary institutions located in the six above-mentioned countries. The list of institutions to which initial invitations were sent was generated using directories of accredited universities, polytechnics and colleges that were specific to each country included in this research effort. In total, social media managers at 501 institutions responded to the initial invitation and agreed to participate in this research effort. This represents a $25 \%$ response rate relative to the total number of initial invitations sent. Social media managers at 336 institutions completed the survey, which represents a $67 \%$ completion rate relative to the 501 institutions that agreed to participate in this research study. A regional breakdown of survey participation is shown in Table II.

TABLE II. SURVEY PARTICIPATION By COUNTRY/REgion

\begin{tabular}{|l|c|c|c|}
\hline & $\begin{array}{c}\text { Number of } \\
\text { invitations } \\
\text { sent }\end{array}$ & $\begin{array}{c}\text { Institutions that } \\
\text { expressed } \\
\text { willingness to } \\
\text { complete survey }\end{array}$ & $\begin{array}{c}\text { Institutions } \\
\text { that } \\
\text { completed } \\
\text { survey }\end{array}$ \\
\hline $\begin{array}{l}\text { Australia and } \\
\text { New Zealand }\end{array}$ & 89 & 40 & 29 \\
\hline Canada & 120 & 42 & 30 \\
\hline $\begin{array}{l}\text { United Kingdom } \\
\text { and Ireland }\end{array}$ & 308 & 58 & 31 \\
\hline $\begin{array}{l}\text { U.S. Two Year } \\
\text { Colleges }\end{array}$ & 764 & 172 & 116 \\
\hline $\begin{array}{l}\text { U.S. Four Year } \\
\text { Colleges }\end{array}$ & 711 & 189 & 130 \\
\hline Total & $\mathbf{1 9 9 2}$ & $\mathbf{5 0 1}$ & $\mathbf{3 3 6}$ \\
\hline
\end{tabular}

A web-survey was an appropriate methodology to assess how communications specialists in the higher education sector employ and manage social media. The questionnaire was designed as a descriptive survey and sought to identify parameters of an appropriate social media framework for an institution like Humber, which recruits students in competition against institutions that are primarily located in the six countries previously identified. As such, Humber's social media strategy is by definition global, and to that end the social media tactics and governance approaches of higher 
education institutions in multiple countries must be considered as the polytechnic develops its social media strategy and governance framework. Employing a web-based descriptive survey was the only practical way to query social media managers located in six countries across three continents.

\section{RESULTS AND DISCUSSION}

\section{A. Governance Structure}

Three survey questions addressed institutional approaches to social media governance. The exact wording of Q15, Q16 and Q18 are included in Table I. Question 15 asked institutions if they permitted individual departments to maintain their own social media channels. Among the 332 survey respondents who answered this question, 93\% allowed departments to maintain their own social media presence, while 7\% did not. Question 16 asked social media managers if their institution published a "social media policy" or some form of "social media best practices" document for individuals who managed institutionally sanctioned social media accounts. Of the institutions surveyed, $78 \%$ reported that they published this kind of document, while $22 \%$ of institutions did not. Question 18 asked institutions if they had some form of "social media steering committee" or a discussion group for social media managers across campus. Just under $39 \%$ of institutions reported that they maintained some sort of vehicle for facilitating cross-campus dialog between social media managers, while about $61 \%$ of respondents did not.

\section{B. Platform Strategy}

While Facebook and Twitter remain among the most popular social media platforms world-wide, academic institutions have embraced a variety of additional social tools at both the institutional and departmental-level. Two questions asked respondents to review a list of ten additional social media platforms prevalent in 2014 and to identify which, if any, they employed at the institutional or departmental-level respectively. The exact wording of Q13 and Q17 are included in Table I. The ten platforms listed as options for each of these questions were: (a) LinkedIn; (b) Google Plus; (c) Tumblr; (d) Instagram; (e) Four Square; (f) Flickr; (g) Pinterest; (h) YouTube; (i) Vimeo; and/or, (j) Snapchat. Among the listed platforms, YouTube was the most commonly employed social media tool besides Facebook and Twitter during the time frame of the survey, with $90 \%$ of institutions using it at college-wide level and $62 \%$ using it at the departmental-level. Nearly $80 \%$ of respondents reported maintaining an institution-wide LinkedIn account, while $50 \%$ reported that one or more individual departments on campus used the networking platform. Instagram was less prevalent at the institutionallevel in late 2014 , with $71 \%$ of respondents maintaining a college-wide account and $59 \%$ reporting its use at the departmental-level. Among the six other platforms included as options for Q13 and Q17, none were used by more than $40 \%$ of surveyed institutions at either the college-wide or departmental-level.

Survey participants were also presented with a pair of questions asking if their institution routinely shared Facebook or Twitter content that originated on other accounts with followers of their college-wide accounts. The exact wording of Q4 and Q10 are included in Table I. Fiftysix percent of respondents stated that they routinely shared Facebook posts from other entities, while $83 \%$ said they routinely retweeted content from other Twitter accounts.

\section{Audience Targeting}

Two survey questions focused on the audience types that surveyed institutions sought to reach via their main Facebook and Twitter accounts. The exact wording of Q6 and Q12 are included in Table I. Both questions asked respondents to select from a list of nine possible audiences: (a) Prospective students; (b) Current students; (c) Faculty and staff; (d) Alumni; (e) Donors; (f) Parents; (g) Guidance counselors; (h) Business and industry; and/or, (i) Local community. Nearly all surveyed institutions reported that they sought to reach current students via both their Facebook and Twitter accounts. A similar number of respondents also identified prospective students as a key audience for their main institutional Facebook and Twitter accounts. The other audience type that a large majority of institutions sought to communicate with were alumni, with $83 \%$ of respondents seeking to connect with graduates via Facebook and almost $80 \%$ seeking to connect via Twitter. A majority of institutions also reported using both Twitter and Facebook to connect with faculty and staff. Surveyed institutions were more likely to employ Facebook to connect with parents $(63 \%)$ as compared to Twitter $(48 \%)$. Conversely, surveyed institutions were nearly twice as likely to employ Twitter $(56 \%)$ to reach business and industry as compared to via Facebook (29\%). Twitter was also substantially more popular among respondents as a tool for communicating with guidance counsellors, with $20 \%$ of surveyed institutions seeking to connect via Twitter, versus $14 \%$ seeking to connect via Facebook.

\section{CONCLUSION}

The aim of this research project was to answer the question, "What are the best practices for a cross-institutional social media framework for the Humber College Institute of Technology and Advanced Learning?" In regards to its platform strategy, Humber's current bundle of institutionwide social media accounts aligns with the platforms most commonly used by competing higher education institutions in Canada, the United States, Australia, New Zealand, Ireland, and the United Kingdom. In addition to Facebook and Twitter, a significant majority of colleges and universities maintain an institutional-level presence on three other social media platforms: YouTube; Instagram; and LinkedIn. Humber is active on all of these aforementioned social media platforms at both the college-wide and departmental-level and thus the polytechnic has a basis for competitive parity when engaging with potential students and other stakeholders via social media. Moving forward, Humber's central marketing team will not need to adopt any new social media platforms as the college moves to establish a formalized social media governance framework and crossinstitutional strategy for the use of digital media platforms.

This research project has revealed, however, that Humber lags behind a significant number of higher education institutions across the globe with respect to the maturity of its social media governance structure. A large number of 
Humber's competitors have established a comprehensive social media governance framework that allows those universities, colleges, and polytechnics to align all of their social media activities across campus with their institutional communications strategy. A large majority of Humber's competitors have already developed a "social media policy" or some form of "social media best practices" document for individuals who manage institutionally sanctioned social media accounts. Furthermore, a substantial number of Humber's competitors already maintain some sort of functional group for facilitating cross-campus dialog between social media managers, which in turn allows those competing institutions to more optimally target the sorts of audiences that can be reached via platforms such as Facebook, Twitter, Instagram, YouTube and LinkedIn.

In order to maintain operational parity with its competitors across the globe, it is recommended that Humber form a social media steering committee that includes appropriate representation from all divisions, schools and departments that are actively engaging with college stakeholders via social media. It is further recommended that this functional group be tasked with advising Humber's senior administration on three key issues: (a) How the college allocates social media related resources on a long term basis; (b) Identifying protocols, supporting documentation, and training resources that will support social media managers in shaping a consistent user experience across all Humber-sanctioned social media channels; and, (c) Establishing consensus on which social media functions should be managed centrally versus those that should be handled at the departmental-level. Taken together, these recommendations will help Humber cultivate an organizational climate vis-à-vis social media that will lead the institution to maximize the impact of social media tools in the furtherance of the polytechnic's larger strategic goals.

\section{REFERENCES}

[1] H. C. I. of T. and A. Learning, “2013-2018 Strategic Plan,” 2013. [Online]. Available: http://humber.ca/strategicplanning/sites/default/files/humbercollege strategic-plan 2013 2018.pdf. [Accessed: 14-Sep-2018].

[2] H. C. I. of T. and A. Learning, "2016-2017 Annual Report."

[3] H. C. I. of T. and A. Learning, "Social media directory." [Online]. Available: https://web.archive.org/web/20141106042726/https://www.humb er.ca/social-media-directory/social-media-directory. [Accessed: 14-Sep-2018].

[4] H. C. I. of T. and A. Learning, "Gearing up for the winter semester." [Online]. Available: https://twitter.com/humbercollege/status/1102242315. [Accessed: 14-Sep-2018].

[5] H. C. I. of T. and A. Learning, "Some pictures of Humber's North Campus," 2009. [Online]. Available: https://www.facebook.com/humbercollege/posts/50756655761/. [Accessed: 14-Sep-2018].

[6] K. Yeung, "LinkedIn is 10 years old today: Here's the story of how it changed the way we work," The Next Web, 2013. [Online]. Available: http://thenextweb.com/insider/2013/05/05/linkedin10-years-social-network/. [Accessed: 14-Sep-2018].

[7] S. Phillips, "A brief history of Facebook," The Guardian, 2007.

[8] N. Carlson, "The real history of Twitter," Business Insider, 2011. [Online]. Available: http://www.businessinsider.com/howtwitter-was-founded-2011-4. [Accessed: 14-Sep-2018].

[9] M. Chafkin, "Can Ben Silbermann turn Pinterest into the world's greatest shopfront?," Fast Company Design. [Online]. Available: http://www.fastcodesign.com/1670681/ben-silbermann-pinterest. [Accessed: 14-Sep-2018].

[10] B. Riley-Smith, "How Instagram took over the world in just three years," The Telegram," 2013. [Online]. Available: http://www.telegraph.co.uk/technology/10355980/How-

Instagram-took-over-the-world-in-just-three-years.html.

[Accessed: 14-Sep-2018].

[11] O. Waxman, "The first YouTube video was uploaded 10 years ago," Time Magazine, 2015.

[12] M. Sippey, "Vine: A new way to share video," Twitter Blog, 2013. [Online]. Available: available: https://blog.twitter.com/2013/vine-a-new-way-to-share-video. [Accessed: 14-Sep-2018].

[13] J. Colao, "Snapchat: The biggest no-revenue mobile app since Instagram," Forbes, 2012.

[14] R. Smith, "The role of social media in higher education marketing," Boston Interactive, 2015. [Online]. Available: https://www.bostoninteractive.com/blog/industries/social-mediahigher-education-marketing. [Accessed: 14-Sep-2018].

[15] A. Lenhart, "Teens, social media \& technology overview 2015," Pew Research," 2015. [Online]. Available: http://www.pewinternet.org/2015/04/09/teens-social-mediatechnology-2015/. [Accessed: 14-Sep-2018].

[16] E. C. and M. Stagno, "Higher education marketing: A study on the impact of social media on study selection and university choice," Int. J. Technol. Educ. Mark., vol. 2, no. 1, pp. 41-58, 2012.

[17] C. D. et Al, "The role of brand attachment strength in higher education," J. Bus. Res., vol. 69, no. 8, pp. 3049-3057, 2016.

[18] R. Choudaha, "Social media in international student recruitment," AIEA Issue Brief, 2013. [Online]. Available: http://www.aieaworld.org/assets/docs/Issue_Briefs/social_media_ recruitment_issue_brief2013march.pdf. [Accessed: 14-Sep2018].

[19] C. B. et Al, "How Canadian universities use social media to brand themselves," Tertiary Education and Management, 2014. [Online]. Available: http://dx.doi.org/10.1080/13583883.2013.852237. [Accessed: 14Sep-2018].

[20] M. T. and G. Westerman, "Governance: A central component of successful digital transformation," Capgemini Consulting, 2012. [Online]. Available: https://www.capgemini.com/wpcontent/uploads/2017/07/Governance_A_Central_Component_o f_Successful_Digital_Transformation.pdf. [Accessed: 14-Sep2018].

[21] G. Kane, "Balancing tradeoffs in social media," 2016. [Online]. Available: http://sloanreview.mit.edu/article/balancing-tradeoffsin-social-media/. [Accessed: 14-Sep-2018].

[22] M. Ansaldo, "Four components of a social media governance model," PC World, 2014. [Online]. Available: http://www.pcworld.com/article/250043/4_components_of_a_soc ial_media_governance model.html. [Accessed: 14-Sep-2018].

[23] P. M. and P. Smith, "Social media governance: Harnessing your social media opportunity," $P w C, 2014$. [Online]. Available: http://www.pwc.co.uk/en_UK/uk/assets/pdf/social-mediagovernance.pdf. [Accessed: 14-Sep-2018].

[24] C. L. and J. Bernoff, Groundswell: Winning in a world transformed by social technologies. Boston: Harvard Business Review Press, 2011.

[25] G. K. et Al, "Strategy, not technology, drives digital transformation," MIT Sloan Management Review, 2015. [Online]. Available: http://sloanreview.mit.edu/projects/strategy-drivesdigital-transformation/. [Accessed: 14-Sep-2018].

[26] C. Barrows, "Centralized or decentralized: The hybrid social media strategy," Slideshare Presentation, 2014. [Online]. Available: http://www.slideshare.net/cgbarrows/centralized-ordecentralized-the-hybrid-social-media-strategy-40564984. [Accessed: 14-Sep-2018].

[27] M. Piskorski, A social strategy: How we profit from social media. Princeton. New Jersey: Princeton University Press, 2014. 